\title{
Introduction of an Improved Attorney System to Spread the Problem Solving Process in Manufacturing Field
}

\author{
제조 현장 문제해결 프로세스 확산을 위한 \\ 개선 변리사 제도 도입 \\ Dong Seok $\mathrm{Oh}^{1}$, Yong Won Song ${ }^{2}$ \\ 오동석 ${ }^{1}$, 송용원 ${ }^{2}$ \\ ${ }^{1}$ Engineer, 28356 SK Hynix Semiconductor Co., Ltd., 120, SK-ro, Heungdeok-gu,Cheongju-si, \\ Chungcheonbuk-do, Korea, dongseok.oh@sk.com \\ ${ }^{2}$ Professor, Dept. Nano \& Semiconductor Engineering, Korea Polytechnic Univ., Sangidaehak-ro, \\ Siheung-si, Gyeonggi-do, Korea, ywsong@kpu.ac.kr
}

Corresponding author: Dong Seok Oh

\begin{abstract}
Numerous companies have begun to adopt a variety of methodologies for fast andaccurate problem solving. Among them, six sigma, which is a statistical approach, was introduced, but thestatistical method, which requires obtaining results from many experiments, was difficult to apply to sites where production is the top priority. As an alternative, the theory of inventive problem solving (TRIZ), which has beenintroduced to the research institute and has a good effect, is being introduced for field problem solving. However, it was not easily distributed to engineers unfamiliar with the new methodology as they had difficulty in applying them to the field. In this paper, we studied a problem solving process that transformed TRIZ that can be applied to various problem situations. This problemsolving process was developed to provide a guide to quickly and easily analyze the cause and to present creative ideas using TRIZ. In addition, in order to spread this problem-solving process, it was developed as a creative problem-solving methodology that can be effectively utilized in industrial sites by combining the patent attorney system.
\end{abstract}

Keywords: QC Story, 6 Sigma, TRIZ, Improving Attorney, Problem Solving

요약: 수많은 기업들은 빠르고 정확한 문제해결을 위해 다양한 방법론을 도입하고 있다. 그중 통계적인 접근 방법인 6시그마를 도입 하였지만, 많은 실험으로 결과를 얻어야 하는 통계적 방법은 생산을 최우선으로 하는 현장에는 적용이 어려웠다. 대안으로 주로 대기업에서 연구소 에 도입하여 좋은 효과를 얻은 창의적 문제해결 이론인 트리즈(TRIZ)를 현장 문제해결을 위해 적용하고 있다. 하지만 새로운 방법에 익숙하지 않은 엔지니어들은 현장 적용에 어려움을 겪 으면서 쉽게 활용하지 못했다. 본 논문에서는 트리즈를 다양한 문제 상황에 적용시킬 수 있도 록 문제해결 프로세스를 연구하였다. 이 문제해결 프로세스는 원인분석을 쉽고 빠르게 할 수 있는 가이드를 제공하고 트리즈를 활용한 창의적인 아이디어가 제시될 수 있도록 개발되었다. 또한 이 문제해결 프로세스를 확산시키기 위해 변리사 제도를 결합하여 산업현장에 효율적으

Received: December 08, 2020; $1^{\text {st }}$ Review Result: January 22, 2021; $2^{\text {nd }}$ Review Result: March 12, 2021 Accepted: April 30, 2021 
로 활용할 수 있는 방법론으로 제시하였다.

핵심어: QC 스토리, 6 시그마, 트리즈, 개선 변리사, 문제해결

\section{1. 서론}

\section{1 기존 문제해결 프로세스의 문제점}

산업 현장에서 사용하는 문제해결 프로세스는 $\mathrm{QC}$ 스토리, 6시그마, 창의적 문제해결 이론(트리즈) 등이 있다. 그중 현장에서 주로 사용하는 $\mathrm{QC}$ 스토리는 문제를 단계별로 수행하도록 하는 정형화된 프로세스로써 과거의 정형화된 문제 또는 유사한 문제에는 유용한 접근법이다. 하지만 정형화 되지 않거나 다양한 접근이 필요한 현장의 문제해결 과정은 발생된 문제의 상황에 따라 프로세스를 다르게 적용하여야 하는데, 정형화된 문제해결 프로세스를 교육 받은 현장 구성원들은 불필요한 단계를 중복으로 수행해야 하는 문제점이 있다. 이러한 $\mathrm{QC}$ 스토리는 문제해결을 수행한 후 줄거리를 설명 또는 발표하기 위해 개발된 것으로 실제 문제해결을 위한 프로세스와는 차이가 있다. 즉, 문제해결 프로세스가 발생된 문제를 해결하기 위해 적절하게 쓰이기보다는 이미 개선된 결과를 역으로 프로세스에 맞추어 최종 결과 보고서나 논문 발표 등으로 사용하는 경우가 많은 실정이다.

이상복(Lee, 2014)은 보고서나 발표용으로 사용되는 프로세스를 시시각각으로 변화하고 분초를 다투는 생산현장에 적용하는 것은 무리가 있다고 판단하고 있다. 또한 특성이 다양한 산업계는 복잡하고 정형화된 문제해결 프로세스에 맞추어 신속하게 문제를 해결하는 것은 현실적으로 모순된 상황으로 보고 있다고 하였다. 그리고 한국의 품질 분임조 활동에서 사용되는 문제해결 프로세스의 보여주기식 활동은 자연스럽게 소멸되거나 구성원들의 자발적인 개선 활동 참여를 이끌어 낼 수가 없다고 하였다[1].

김창남(Kim, 2012)은 $\mathrm{QC}$ 스토리가 주제 선정에서부터 반성 및 향후 계획까지 정형화된 10 단계에 의해 실행되므로 활동상 어려움이 발생한다고 주장하였다. 또한 6시그마는 통계적인 문제해결 능력 습득에 장기간 교육훈련이 필요하고, 현장 구성원이 해결하기에는 문제해결 프로세스의 단계와 분석 절차가 복잡하고, 이러한 과정에서 불필요한 통계 기법을 억지로 사용하는 폐단이 발생한다고 주장하였다[2].

이강인(Lee, 2011)은 현장 문제해결 프로세스에 적용하고 있는 $\mathrm{QC}$ 스토리가 다양한 기업의 특성에 맞지 않는 형식적인 활동을 하고 있다고 지적하였다. 이러한 문제점은 발표 원고를 인위적으로 작성하는 부작용의 악순환을 가져오는 원인이라고 주장하였다[3].

$\mathrm{SK}$ 하이닉스 국가 품질명장 협의회는 기업 내부에서 주로 사용하고 있는 $\mathrm{QC}$ 스토리의 사용상 문제점을 다음의 6가지로 요약하였다.

(1) 현장의 대부분 과제는 10 단계의 프로세스가 불필요하다.

(2) 제조 현장의 문제 해결은 대부분 불합리를 해결하는 개선 제안 중심의 활동이다.

(3) 엔지니어들은 한 명이 다수의 과제를 진행하며 중복으로 과제를 추진한다.

(4) 활동 주제는 대부분 부서의 목표 달성을 위해서 선택되거나 주어진다. 
(5) 개선 부품의 발주, 제작 등의 일정으로 중복적인 과제 수행이 아니면 1 년에 2 개 이상의 과제 추진은 현실적으로 어렵다.

(6) 빠른 과제 추진을 위해 $\mathrm{QC}$ 스토리의 스텝은 대부분 중복으로 실행된다.

수많은 기업들은 $\mathrm{QC}$ 스토리 외에도 다양한 문제해결 접근법을 도입하였다. 그중 6 시그마의 통계적 분석 기법을 활용하여 성공한 기업을 벤치마킹하여 앞 다투어 적극 도입했지만 실제 현장에 정착시키는데 성공한 기업은 드물다. 주요 이유로는 의미 있는 통계적 결과를 얻기 위해서는 확률적으로 수많은 실험을 해야 하는데 생산을 최우선으로 하는 현장 상황에서 수많은 실험을 위한 적극적인 대처가 어렵기 때문이다. 결국 어렵게 배워서 실제 현장에서 활용이 어려워 실무적으로 통계적 실험이 가능한 부서에서만 활용하고 일선 현장에서는 거의 활용되고 있지 않는 문제가 있다.

창의적으로 문제에 접근하는 트리즈 또한 많은 대기업들이 도입하였으며 주로 개발 부서와 연구소에서 유용하게 활용되고 있다. 창의적인 문제해결 방법론으로 트리즈는 매우 유용하지만 타 방법론에 비해 상대적으로 제대로 이해하는 것이 어렵다. 현장에서 활용이 가능할 정도로 트리즈를 습득하려면 긴 교육 시간과 높은 비용을 부담해야 하므로 주로 대기업 중심으로 도입하여 활용이 되고 있다. 트리즈가 중소기업에도 매우 적합한 방법론이라고 생각하지만 운영상 여건이 열악한 중소기업의 현장은 교육의 기회조차 갖기 어려운 실정이다.

\section{2 현장 개선 활동 확산의 문제점}

기업의 현장 개선 활동이 축소된 이유는 다양하다. 가장 많이 거론되는 것으로 최고 경영자의 무관심과 개선 담당 임원이나 관리자들의 잘못된 이해 등을 들고 있다.

이상복(Ree, 2014)교수는 품질 분임조 개선 활동이 축소되는 이유 중 품질 분임조 개선 활동 자체의 문제점으로 개념, 도입 및 운영, 의식, 인적자원의 문제를 들었다. 개념상 문제는 테마 선정이 부적절하고, 전원 참가 원칙에 치우쳐 무리한 활동을 수행하는 것과 자주성을 오해해서 회사와 마찰을 일으키는 점이 있으며, 현장의 구성원들에 대한 관심과 배려 그리고, 활동 시간의 부족, 성과에 대한 보상의 부족이 품질 분임조 개선 활동 과정의 저해 요소라고 강조했다. 인식 문제는 경영자와 관리자의 인식 부족과 현장 직원들의 마인드 부족으로 인해 자주적이고, 자발적이지 못한 부분과 동기 부여의 부족함을 들었으며, 인적 자원의 문제는 분임조장과 추진자의 능력 부족으로 올바른 지도가 되지 못하는 점을 지적하였다[4].

박완복(Park, 2020)국가 품질명장은 현장의 작업자들은 $\mathrm{QC}$ 스토리 작성이 복잡하고, 성과 도출에 직접 관련이 없는 프로세스에 맞추어 자료를 작성하는 것이 가장 어려운 작업이라고 하였다[5].

오동석(Oh, 2016)국가 품질명장은 실제 현장의 우수한 개선 활동은 소수의 혁신적인 사고를 가진 구성원들을 중심으로 이루어지고 있으며 대부분의 구성원들은 혁신 활동과 개선에 관심이 없거나 잘 알지 못한다는 것을 확인하였다[6].

현장에 대부분의 구성원들은 직접 업무 외에는 관심이 부족하다. 특히 올바른 지식으로 혁신적인 사고를 가진 우수한 지도사가 부족하기 때문에 현장 개선 활동에 실제 도움을 주고 올바른 방향으로 지도해 주거나 확산의 기반을 만들어 줄 인적 여건이 
부족한 문제를 가지고 있다.

\section{3 기업의 극복 방안}

현재 대한민국의 경제는 여러 가지 어려움을 겪고 있다. 저렴한 인력과 풍부한 내수를 가지고 밀려오는 중국과 개발도상국들의 위협은 우리나라의 기업들을 압박하고 있다. 또 다시 과거의 영광을 꿈꾸는 선진국가들은 내수 시장의 개선을 위해 까다로운 관문을 만들어 홀로서기 정책을 추진하고 있다. 이러한 세계적인 여파 속에서 국내의 많은 기업들은 현장 개선 활동을 활성화시키기 위하여 수많은 노력들을 해 왔다.

4차 산업혁명 시대는 수많은 문제의 유형들이 나타나기 때문에 정형화 되지 않은 다양한 문제를 다루기 위해 유연성을 확보한 신속하고 정확한 프로세스가 필요하다. 하지만 기존의 문제해결 프로세스로는 어려운 경우가 많기 때문에 기업은 자사에 적절한 문제해결 프로세스가 필요하다.

기업에서 현장 개선 활동을 자율적으로 전파하기 위해서는 자사에 적절한 문제해결 프로세스도 필요하지만 그 보다 중요한 것은 이 문제해결 프로세스를 정확하게 이해하고 수행할 수 있는 내부의 구성원을 충분하게 확보하는 것이 핵심이다.

현장 개선 활동의 근본은 현장에서 직접 생산 활동을 하는 구성원이다. 이 구성원들의 개선 활동은 기업의 우수한 성과와 높은 생산성을 확보 할 수 있게 한다. 하지만 현장에서 일하는 대부분의 직원들은 개선 활동을 잘하기 위한 교육을 받기가 쉽지 않으며 배워도 바로 적용해 보기가 쉽지 않다. 특히 개선 내용을 보고서로 만드는 일은 매우 힘든 일이기 때문에 개선을 해도 표현하지 못하고 그냥 지나가는 경우도 아주 많다.

누구나 한번쯤은 '물어볼 사람이 있었으면 좋겠다' 또는 '내 생각을 잘 표현 하도록 도와줄 사람이 있었으면 좋겠다, 라는 생각을 해보게 된다. 이때 구성원들의 개선을 도와주거나 문서로 표현하는 업무를 도와주는 지도사가 있으면 현장의 구성원들에게는 큰 도움이 될 것이다.

\section{2. 현장 문제해결 프로세스}

\section{1 현장 문제해결 프로세스의 개발}

현장에서 사용할 문제해결 프로세스는 첫번째로 간단해야 한다. 문제해결 프로세스는 [그림 1]과 같이 '문제 분석-개선-정리'의 3 단계의 절차로 구성된다. 아무리 좋은 문제해결 프로세스라 하더라도 복잡한 절차라면 현장에서 사용하기에는 많은 불편함이 있다. 불편하게 되면 해당 프로세스의 사용을 꺼려하게 될 것이고, 사용을 꺼려하게 되면 프로세스는 사라지고 말 것이다. 이 프로세스는 단순한 프로세스이지만 현장의 기초적인 단순 개선부터 테마 과제해결까지 해결할 수 있는 프로세스를 추구한다. 이렇게 문제 해결 프로세스는 간단하게 구성되어야 현장에서 쉽게 접근하고 활용이 가능하다. 


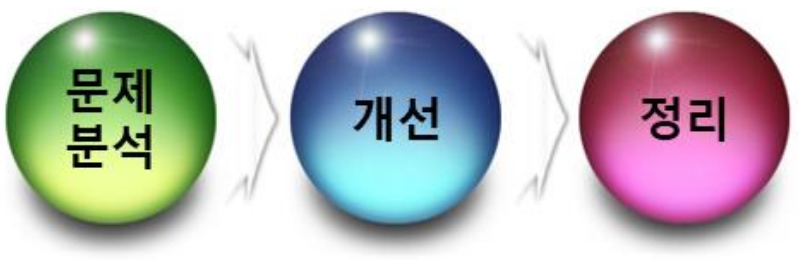

[그림 1] 간단한 문제해결 프로세스

[Fig. 1] Simple Problem Solving Process

두번째는 문제 상황에 따라 선택이 가능한 유연성이 확보되어야 한다. 현장에는 다양한 문제가 존재한다. 현장 문제해결 프로세스는 [그림 2]와 같이 다양한 문제에 대해 상황 별로 대처가 가능한 유연성을 확보한 문제해결 프로세스이다. 현장에는 새롭게 발생하는 문제도 있지만 이미 상황을 알고 있는 문제가 더 많이 존재한다. 현상을 알고 있으나 원인을 알지 못하는 문제, 현상과 원인은 알고 있으나 대처 방안이 없는 문제, 대책 아이디어가 있으나 현실적인 적용이 어려운 문제 등이 있다. 이 문제해결 프로세스는 [그림 3]과 같이 다양한 문제에 대해서 사례별로 절차를 제시하는 것이 장점이다. 이렇게 시작이 다른 다양한 유형의 문제 상황에서 접근법을 달리하여 알고 있는 사실에 대하여 중복적인 분석을 하지 않아도 되는 문제해결 프로세스가 필요하다.

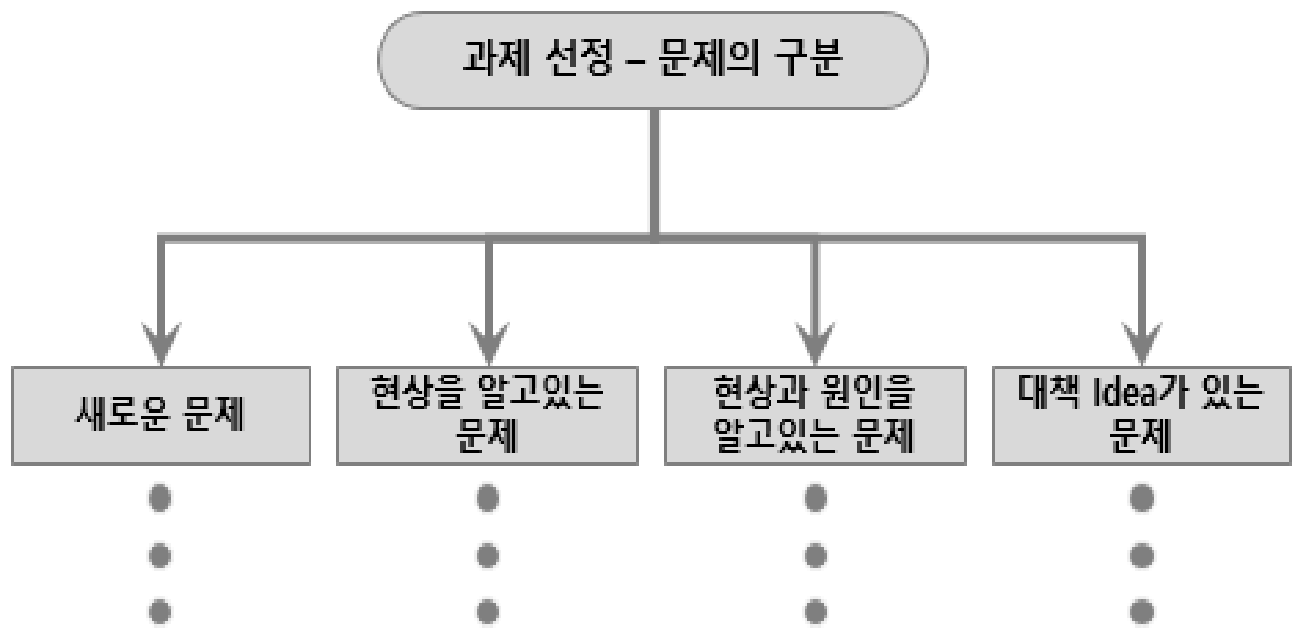

[그림 2] 유연한 문제해결 프로세스

[Fig. 2] Flexible Problem Solving Process

세 번째로는 단계 구분 없이 빠른 문제해결이 되어야 한다. 현장에서는 많은 문제들이 지속적으로 발생하고 있기 때문에 문제를 빠르게 해결하지 못하면 고질적인 문제가 되어 현장에 누적이 된다. 이 문제해결 프로세스는 이러한 점을 고려하여 문제에 대한 원인 분석 과정에서도 동시에 대책을 수립하거나 실행하는 프로세스를 권고하여 개선 과정의 Speed를 확보하였다. [그림 3]에서 프로세스 로드맵을 통해 상세 프로세스를 제시하였지만 과제의 성격에 따라 선택 적용이 가능하다. 즉, [그림 4]와 같이 프로세스는 단계 구분을 
자유롭게 하여 문제해결 프로세스를 적용하는 구성원이 필요한 단계만 선택해서 적용이 가능하기 때문에 빠르면서 효율적인 프로세스가 가능하다.

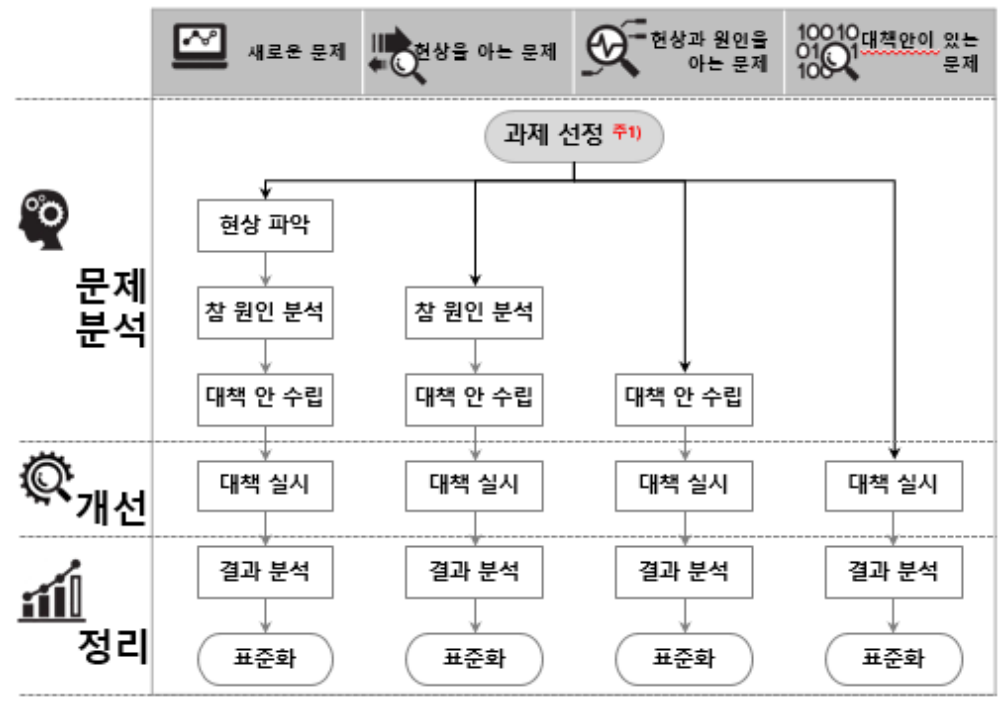

[그림 3] 문제 상황에 따른 프로세스 로드맵

[Fig. 3] Process Roadmap According to the Problem Situation

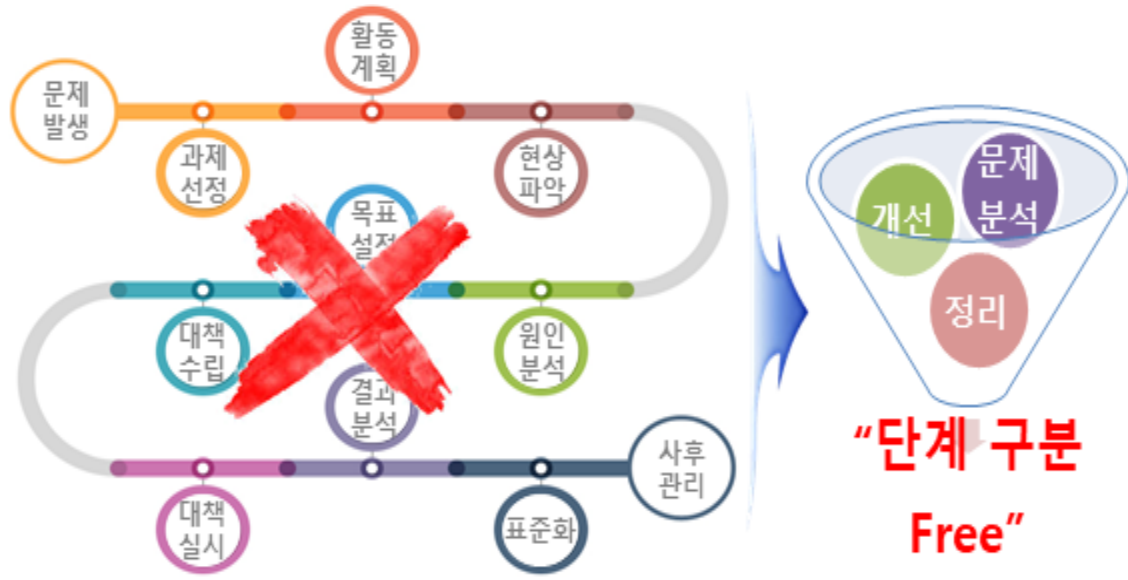

[그림 4] 빠른 문제해결 프로세스

[Fig. 4] Speed Problem Solving Process

네 번째는 타 부서간 협업 활동을 통해 시너지를 극대화 시킬 수 있어야 한다. 프로세스에서 중요한 정보 찾아내는 단계가 문제 분석 단계이다. 그러나 많은 경우 이 과정에서 해당 구성원의 공정, 직무, 역할이 아닌 경우 포기하거나 개선의 질이 떨어지는 경우가 발생한다. 이 문제해결 프로세스는 이 부분의 해결 방법으로 [그림 5]와 같이 과제를 위임하는 방법을 제시하였다. 문제 분석 결과 “우리가 과제를 해결 할 것인가? 전문가에게 위임 할 것인가?” 판단하여 해당 구성원의 공정, 직무, 역할일 경우 직접 
과제를 해결하고 타 공정, 직무, 역할일 경우 과제를 위임하도록 하였다. 전문가에 위임되어 과제가 해결됨으로써 개선의 질이 상승되는 효과가 있다. 특히 공정간, 직무간, 역할 간에 존재하는 장벽을 제거함으로써 유대감이 형성되는 부수적인 효과도 존재한다. 위임을 통한 문제 해결은 시너지를 증폭 시킬 수 있다.

\section{2 현장 문제해결 프로세스 소개}

소개하고자 하는 현장 문제해결 프로세스는 문제 분석-개선-정리의 총 3 단계로 구성되어 있으며 상세 프로세스는 [그림 6]과 같다. 문제 분석 단계는 원하지 않는 현상을 규명하고 근본원인 도출 및 해결 방안을 수립하는 것을 주안점으로 두었고, 개선은 PDCA(Plan-Do-Check-Action) 중 PDC(Plan-Do-Check)까지 수행하는 것을 주안점으로 두었다.

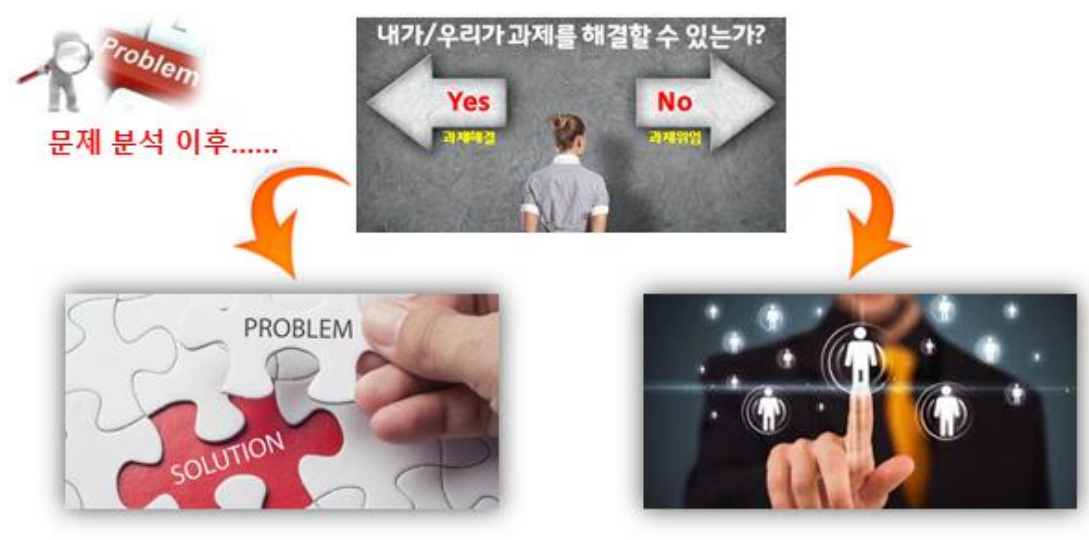

[그림 5] 시너지형 문제해결 프로세스

[Fig. 5] Synergy Problem Solving Process

\begin{tabular}{|c|c|c|c|}
\hline 구분 & (1) 문제 분석 & (2) & 정리 \\
\hline 설명 & $\begin{array}{l}\text { 원하지 않는 현상 규명 } \\
\text { 근본 원인 도출 / 해결 방안 수립 }\end{array}$ & 대책 안 실행 & $\begin{array}{l}\text { 결과 분석 } \\
\text { 표준화 실시 }\end{array}$ \\
\hline \multirow{4}{*}{$\begin{array}{l}\text { 세부 } \\
\text { 단계 }\end{array}$} & $\begin{array}{l}\text { A. 과제 선정 } \\
\quad \text { (배경/일정/목표... 등 }\end{array}$ & A. Plan & \multirow{2}{*}{ A. 결과 확인 } \\
\hline & $\begin{array}{l}\text { B. 현상 파악 } \\
\text { (중점 항목 선정) }\end{array}$ & \multirow{2}{*}{ B. Do } & \\
\hline & C. 참 원인 분석 & & \multirow{2}{*}{ B. 표준화 } \\
\hline & D. 대책 안 수립 & C. Check & \\
\hline
\end{tabular}

[그림 6] 문제해결 프로세스 로드맵

[Fig. 6] Roadmap to the Problem Solving Process 
(1) 문제 분석

A. 과제 선정: 과제 선정 단계는 배경, 일정, 목표 등을 제시하기를 권고한다. 그러나 반드시 제시하여야 하는 것은 아니다. 이미 현장에는 KPI(Key Performance Indicator), 부서 목표, 생산량 등으로 배경, 일정, 목표는 드러나 있기 때문이다.

B. 현상 파악(중점항목선정): 문제해결 프로세스에서 가장 중요한 단계로 문제의 현상을 파악하는 단계이다. 많은 경우 이미 전산화를 통해서 생산량, 불량률 등이 공개되어 있으므로 데이터의 확보에는 큰 문제가 없으나, 현장에서 직접 현물을 보고 현상을 파악하는 3 현에 입각한 파악이 필요하다. 많은 경우 현상 파악 중 원인이 파악되고 바로 대책 안이 도출되어 즉시 개선으로 이어지기 때문이다.

C. 참 원인 분석: 참 원인 분석은 현상 파악에서 중요시 되는 중점 항목에 대한 근본 원인을 파악 하는 단계로, 참 원인 분석과 대책 안 수립을 거의 동시에 생각한다. 즉, 생산 현장에서는 대체로 원인이 파악되면 대책 안은 거의 실시간으로 수립이 되기 때문이다.

D. 대책 안 수립: 참 원인에 대한 개선 수단이나 방법을 강구하는 단계이다. 앞서 참 원인 분석에서 언급했듯이 소개하는 문제해결 프로세스는 참 원인 분석과 대책 안 수립이 거의 동시에 발생한다. 그러나 간과하지 말아야 하는 것은 대책 방안에 대한 부작용을 확인해야 한다는 것이다.

(2) 대책: 대책의 특징은 PDCA(Plan-Do-Check-Action) 중 PDC(Plan-Do-Check)까지만 수행한다. 이것은 소개하는 문제해결 프로세스의 큰 특징 중에 하나인데, 현장은 단 일주일 정도의 점검 결과를 가지고 조치를 하지는 않기 때문이다.

(3) 정리

A. 결과 분석: 현상 파악에서 파악한 데이터 대비 결과 분석을 수행하고, 유 무형 효과를 파악한다.

B. 표준화: 결과 분석을 확인하여 개선한 과제가 표준화의 가치가 있는지를 판단해서, 표준화의 가치가 있다면 표준화를 실시한다.

\section{3 현장 문제해결 상세 프로세스의 특징}

(1) 상세 프로세스 스텝 적용: 문제 상황 별로 선택 적용이 가능하다. 즉, 과제 선정, 현 상 파악, 참 원인 수립, 대책 안 수립, 표준화 등에 대해서는 선택적 적용이 가능하다. 현 장 구성원들이 일을 하다 보면 조직에 의해서 과제가 이미 선정된 경우가 존재하고, 이 미 현상 파악이 된 경우도 있으며, 참 원인 분석까지 모두 이루어지고 대책 안이 수립까 지 된 경우도 있기 때문이다. 표준화의 경우도 표준의 필요 유무를 파악하여 불필요한 경우 선택하지 않을 수 있다.

(2) 문제 분석 단계: 현상 파악 또는 참 원인 분석 과정 중 즉시 개선 가능하다. 즉, 문 제 분석 단계의 모든 단계는 상호 보완되며, 스텝의 전, 후가 없이 거의 동시에 개선으로 이어지는 것이 특징이다. 이와 같은 배경은 현장에서 적용하고 있는 문제해결 방법을 통 해 파악되었다. 현상 파악을 하는 시점에서 바로 원인이 파악되고 개선까지 일사천리로 이루어지는 경험을 많은 현장 구성원들이 피력하였다. 이러한 현장 구성원의 의견을 반 영하였다. 
참 원인 분석에는 주로 특성요인도와 연관도법을 많이 사용하는데 작성 후 다시 정리 해야 보기가 쉽다는 단점이 있다. 그 외에도 원인-결과 분석 등 많은 도구들이 있다. 하 지만 모든 원인 분석은 왜-왜 분석을 바탕으로 만들어져 있기 때문에 현장 직원들은 왜왜 분석의 개념만 알아도 충분히 원인 분석을 할 수 있다. 여기서 많은 직원들은 반드시 최종 원인에 대한 대책만이 올바른 대책이라고 생각한다. 하지만 우리는 문제의 현상을 제거하는 것이 최종의 목적이기 때문에 반드시 최종 원인이 아니어도 중간 단계의 원인 에서도 문제를 해결할 수 있다.

(3) 참 원인 분석과 대책 안 수립 통합: 참 원인 분석과 동시에 대책 안을 도출하는 것 이 특징이다. 보통 참 원인 분석 단계를 거치게 되면 현장의 기술이 노련한 구성원들은 이미 대책 안이 도출이 되는 경우가 많다. 이 역시 현장 구성원의 의견을 반영하였으며, 현장에서 적용되고 있는 문제해결 프로세스를 일반화 한 것이다. 이 과정에서의 아이디 어는 일반적인 조치이기 때문에 예상되는 부작용인 모순이 드러날 수 있다. 이 단계에서 모순에 의한 문제가 모델링 되면 창의적 문제해결 이론(트리즈) 기법을 적극 활용하여 창 의적인 아이디어를 제시할 수 있다.

(4) 개선 단계: $\mathrm{P}(\mathrm{Plan}), \mathrm{D}(\mathrm{Do}), \mathrm{C}($ Check)를 수행하고, $\mathrm{A}$ (Action)는 정리 단계에서 일괄 수행한다. 사실 개선 단계의 점검(Check) 단계를 수행하고 곧바로 표준화를 수행하는 조치(Action) 단계를 수행하는 회사는 없을 것이다. 이 문제해결 프로세스에서도 역시 개선이 되었다면 일정기간 생산을 해보고 안정적일 때 표준화를 실시한다. 이러한 과정을 실제 반영하기 위해서 정리 단계의 마지막에 표준화 단계를 삽입했다. 물론 프로세스의 마지막은 이러한 것들을 논리적으로 잘 정리한 최종 보고서 일수도 있겠지만 제공되는 표준 양식을 잘 활용한다면 보고서를 위한 별도의 시간은 불필요할 것이다. 사실 이런 단계가 지금까지 없었던 새로운 것은 아니다. 우리가 익숙하지 않을 뿐이다. 아마도 문제해결 프로세스에 익숙한 사람이나, 태생부터 천부적인 자질을 타고난 사람이라면 시작 단계부터 익숙하게 진행할 것이다. 하지만 익숙하지 않은 우리는 눈에 보이는 현상에 대한 조치로 문제를 해결하려고 할 것이다. 그 결과가 효율적인지 아닌지는 상관없이 말이다. 물론, 때로는 경험이 가장 효율적일 때도 있겠지만 복잡한 문제에 대해서는 경험만으로는 한계가 있을 것이다. 그러므로 지금까지 경험으로만 문제를 해결하는 경향이 강했다면, 지금부터는 문제해결 프로세스에 근거해서 문제를 풀어가려는 습관을 만들어 나가야 한다. 소개하는 현장 문제해결 프로세스의 세부 단계는 9단계로 구성이 되어 있지만 이를 모두 적용할 수도 있고, 일부만을 적용해서 문제를 해결 할 수도 있다. 즉, 프로세스 적용은 현장 문제 상황 별로 선택하여 적용할 수 있다.

\section{4 현장 문제해결 프로세스 예시}

다음은 현장 문제해결 프로세스에서 문제 분석의 과정을 레이저 포인트의 예시를 통하 여 설명을 하고자 한다.

1단계(현상): 레이저 포인트에서 빔이 나오지 않는다 


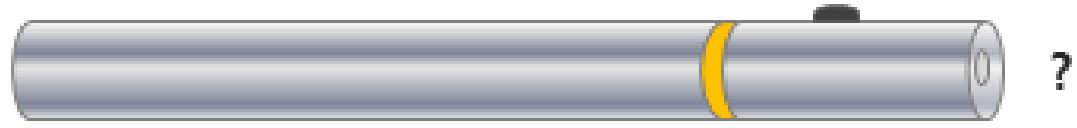

[그림 7] 1 단계 - 현상

[Fig. 7] Stage 1-Phenomenon

2단계(중점 항목): 층별 가능한 항목 중에서 현상을 발생시킨 중점 항목을 찾는다.

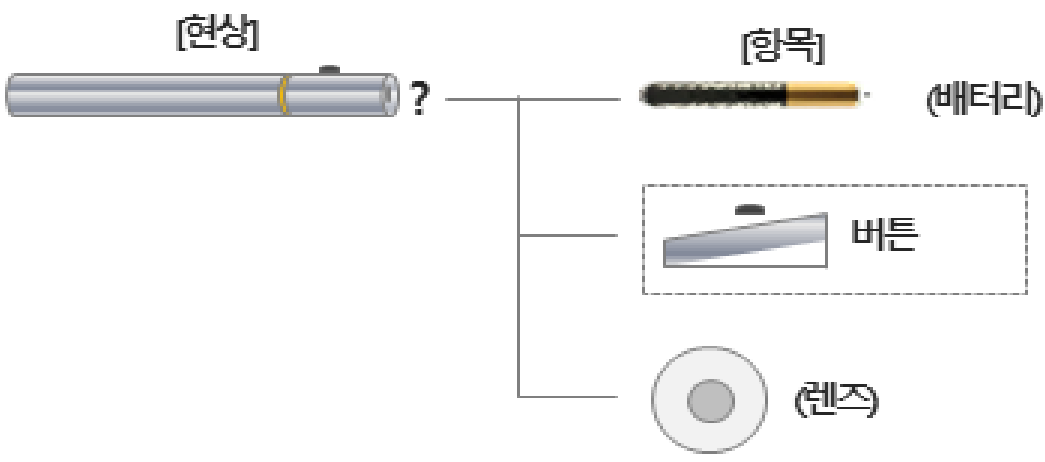

[그림 8] 2 단계 - 중점 항목 선정

[Fig. 8] Stage 2-Selection of Key Items by Levels

3단계(핵심 항목): 마지막으로 도출된 최종 원인이 되는 말단 부품을 찾는다

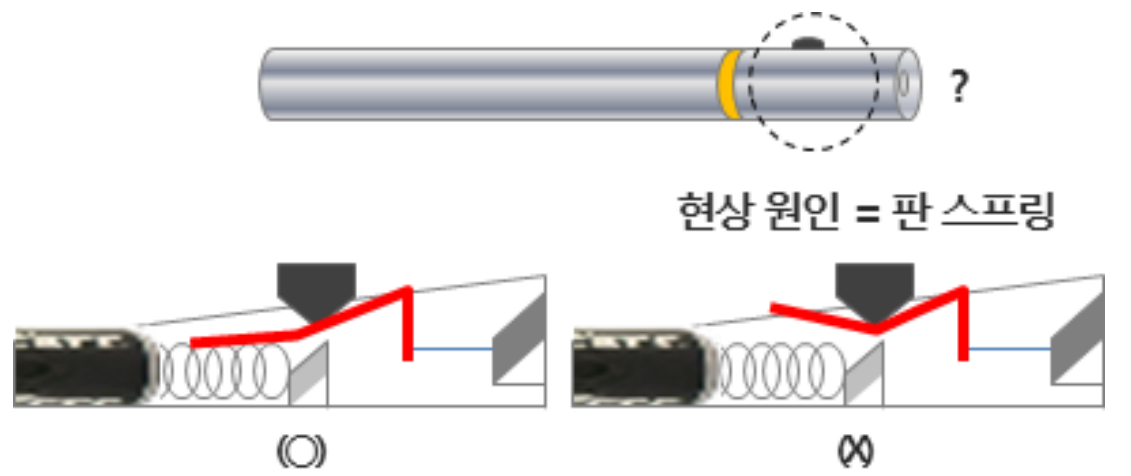

[그림 9] 3 단계 - 핵심 항목 선정

[Fig. 9] Stage 3-Selection of Key Items

4단계(참 원인 분석 및 대책 안 수립): 이렇게 도출된 핵심 항목에 대하여 왜-왜 분석을 기반으로 참 원인 분석을 실시하고 이 과정에서 원인 사슬을 끊을 수 있는 조치를 대안으로 제시할 수 있다. 


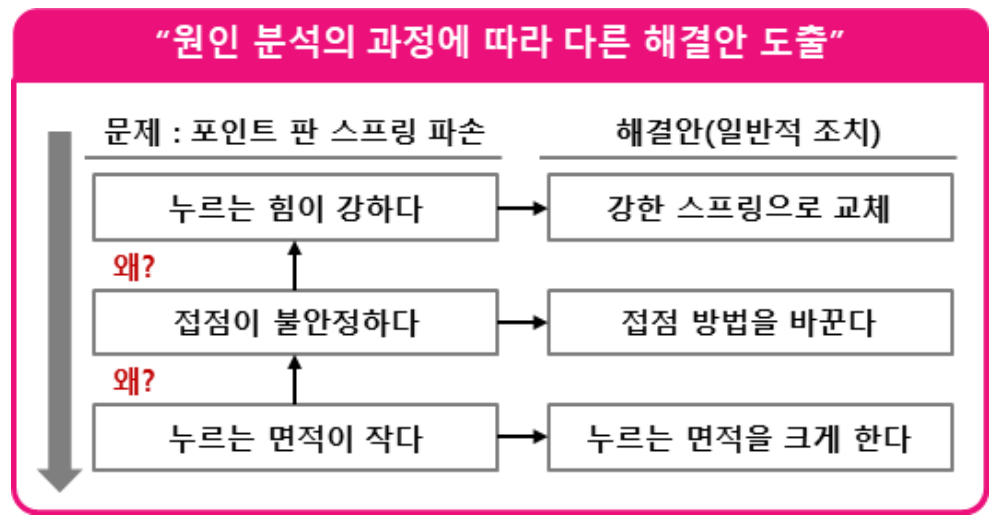

[그림 10]4 단계 - 참 원인 분석 및 대책 안 수립

[Fig. 10] Stage 4-Selection of Key Items

[그림 10]과 같이 최종 원인은 누르는 면적이 작기 때문에 면적을 크게 하는 대안이 제 시될 수 있다. 하지만 불안정한 접점이라는 원인에서 접점 방법을 바꾸는 대안도 제시 될 수 있으며 오히려 이러한 대안이 근본 대책에 가까울 수 도 있을 것이다.

이렇게 제시된 대책은 일반적인 조치이기 때문에 쉬운 문제는 바로 해결이 가능하지만 부작용이 있는 대책은 이때 모순이 나타난다. 이와 동일하게 개선 단계에서의 모순은 개 선을 실행하는 단계에서 부작용과 함께 모순이 나타나기 때문이 현장 직원들은 이때 나 타나는 모순 상황을 트리즈의 모순 분석을 통하여 해결 아이디어를 빠르게 제시할 수 있 다.

소개하는 현장 문제해결 프로세스는 반도체 제조업에서 개발하고 적용해본 사례이다. 그렇기 때문에 기업마다 업무적 특성이 다르다는 점을 고려한다면 소개하는 프로세스가 모두 적용이 가능하다고 장담 할 수 는 없다. 하지만 기업은 자사의 업무 특성과 형식을 연구하여 자사에 맞는 현장 문제해결 프로세스에 대한 고민은 충분히 필요할 것이다.

이렇게 문제해결 프로세스를 현장에 맞게 개발해도 실제 현장에서 사용하는 구성원이 없다면 이것 또한 큰 문제일 것이다. 또한 사용을 했다고 하더라도 표현하는 방법을 알 지 못해서 문서 작성의 어려움이 있는 구성원들은 더욱 활용에 대한 표현이 어려울 것이 다. 이 문제는 시용하지 않거나 표현하지 못하는 구성원의 문제가 아니라 방법론을 제시 하면 모두가 사용할 수 있을 것 이라고 잘못 알고 있거나 사용할 수 없는 구조적인 문제 를 해결해 주지 않는 경영진과 관리자의 잘못된 의식이 더욱 큰 문제일 것이다.

이 논문에서는 이러한 제도나 방법론을 현장에 자연스럽게 적용될 수 있도록 하기 위한 방안을 제시하고자 한다.

\section{3. 개선 변리사 제도}

\section{1 특허 변리사와 개선 변리사}

2005년 비즈니스 지식 포털 비즈몬이 직장인 872명을 대상으로 한 문서 작성의 어려움에 대한 설문조사 결과, 전체 응답자의 $72.1 \%$ 가 업무상 문서 작성에 어려움을 
느끼고 있다고 답했다[7].

박혁종(Park, 2010)은 국내 대기업의 인사 담당자들에게 직장인들이 성과를 내기 위해서 필요한 항목을 조사한 결과 가장 필요한 것이 문서 작성 능력이 가장 필요함을 강조했다. 문서 작성 능력의 부족은 이공계 전공자나 엔지니어들이 더욱 심하게 취약한 것으로 나타난다고 주장했다[8].

변리사법 제 3 조에 의하면 변리사는 산업 재산권인 특허권, 실용신안권, 디자인권, 상표권과 저작권, 신지식 재산권 등의 권리 취득이나 분쟁 해결에 관련된 제반 업무를 수행하는 사람을 일컫는다. 변리사는 산업 재산권의 권리화를 위해 발명 또는 출원을 원하는 사람과 상담한다. 이 후 출원서를 작성하고, 특허청에 권리 등록 절차를 대리한다. 출원서의 체계적인 작성은 변리사 업무 비중에서 가장 큰 부분이다. 발명, 고안 등의 추상적인 아이디어를 구체적으로 작성함으로써 권리 범위를 정하는데 큰 역할을 한다[9].

[그림 11] 은 특허 변리사의 프로세스이다.

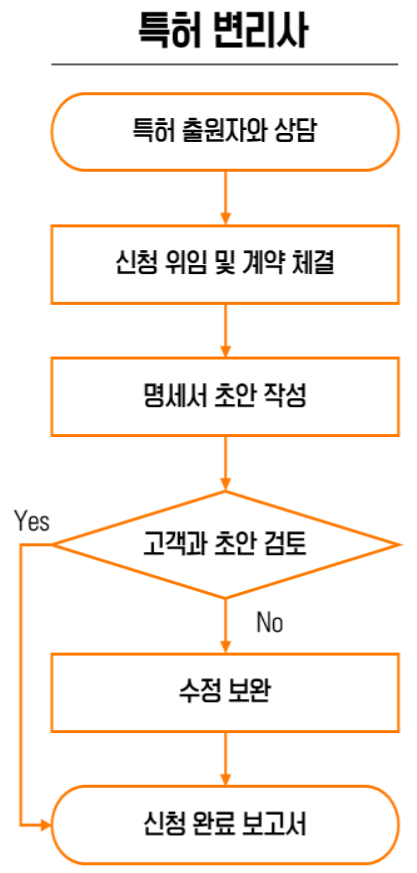

[그림 11] 특허 변리사 프로세스

[Fig. 11] Process - Patent Attorney

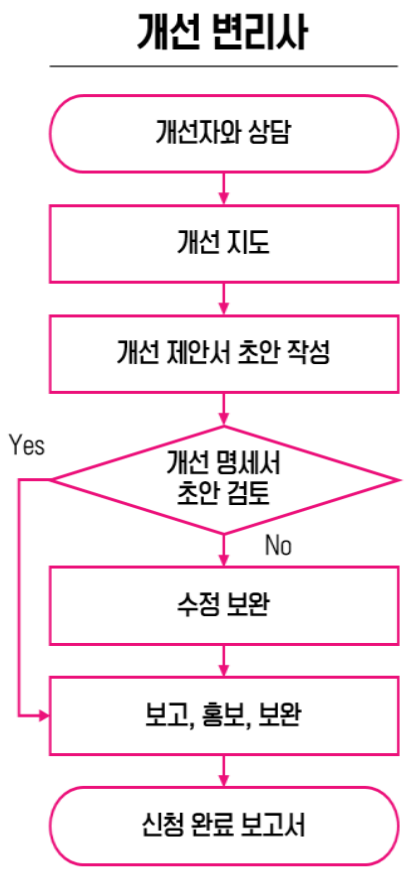

[그림 12] 개선 변리사 프로세스

[Fig. 12] Process - Improving Attorney

개선 변리사란 현장 개선 활동에 대한 지도와 병행하여 최종 보고서 작성을 대리하고 사내 표준 등록에 대해 심의, 등록하는 사람을 말한다. [그림 12]는 개선 변리사의 업무 프로세스를 표현한 것이다. 특허 변리사가 고객의 아이디어나 기술에 대한 출원서를 작성하는 것과 같이 개선 변리사는 품질 개선 내용에 대한 과정 지도와 함께 제안서를 체계적으로 작성하고, 개선과 관련된 선행 표준을 조사하고 표준의 범위를 확인 후 등록하는데 도움을 준다. 


\section{2 개선 변리사를 통한 현장 문제해결 프로세스의 정착}

앞에서 설명한 현장 문제해결 프로세스를 현장에 정착시키기 위해서는 탁월한 성과와 혁신적 사고를 가진 우수한 구성원의 노력이 필요하다. 이 구성원이 주변 구성원들의 개선을 도와주거나 문서로 표현하는 업무를 도와주는 지도사가 있으면 현장의 구성원들에게는 큰 도움이 될 것이다.

조직에서는 언제나 다양한 지식을 가지고 뛰어난 성과를 많이 내는 구성원들이 일부 존재한다. 이 구성원들이 본인만의 성과로 회사에 기여를 하는 것 또한 회사에서는 큰 인적 재산이 될 것 이다. 하지만 이 우수한 구성원이 주변의 구성원들의 개선을 도와준다면 회사는 더 많은 성과를 창출할 수 있을 것이다. 기업은 이 구성원을 개선 변리사로 육성하여 역할을 수행 하도록 지원해야 한다. 이 구성원은 조직에서 혁신적 사고와 많은 지식을 가지고 있으며 문제 해결 능력이 다른 구성원들 보다 매우 우수하기 때문에 통계적 지식과 창의적 문제해결 이론(트리즈)등을 다양하게 학습하면 성과는 극대화 될 것이다. 특히 통계적 기법과 트리즈는 특성상 학습이 어렵고 현장 실무에 직접 적용하는 것은 더욱 어렵다. 그러나 육성된 개선 변리사는 혁신적 사고를 가지고 있기 때문에 반드시 스스로 그 해답을 찾을 것이다. 이렇게 육성된 개선 변리사가 다양한 문제해결 도구를 바탕으로 현장 문제해결 프로세스를 활용한다면 창의적인 아이디어를 바탕으로 실행되는 개선은 주변의 관심을 끌기에 충분할 것이다.

개선 변리사는 혁신적 사고를 바탕으로 문제 분석 단계부터 개선의 다양한 접근법을 다루기 때문에 현장 문제해결 프로세스라는 도구가 주어지면 그 성과가 극대화 될 것이다. 이렇게 본인이 터득한 노하우를 조직의 지원을 받으면서 스스로 하위 구성원들에게 노하우를 전파를 하게 되며 조직은 선순환 구조를 만들게 된다.

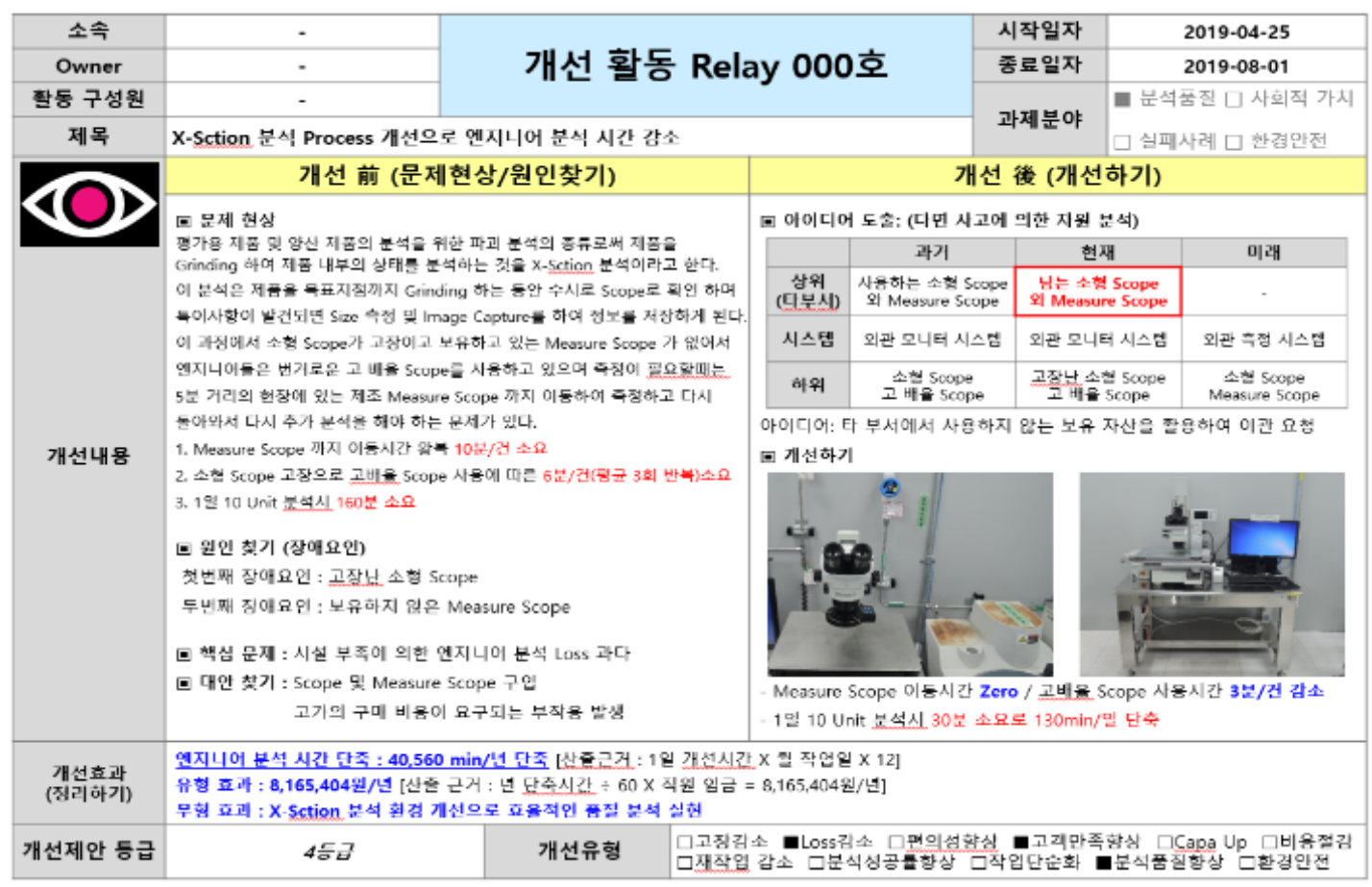

[그림 13] 현장 사례 1

[Fig. 13] Field Case 1 
[그림 13] 현장 사례 1은 문제 해결을 위해 타 부서의 자원을 활용하여 추가 비용 없이 회사의 여유 자산으로 문제를 해결한 타 부서 협조 사례이다.

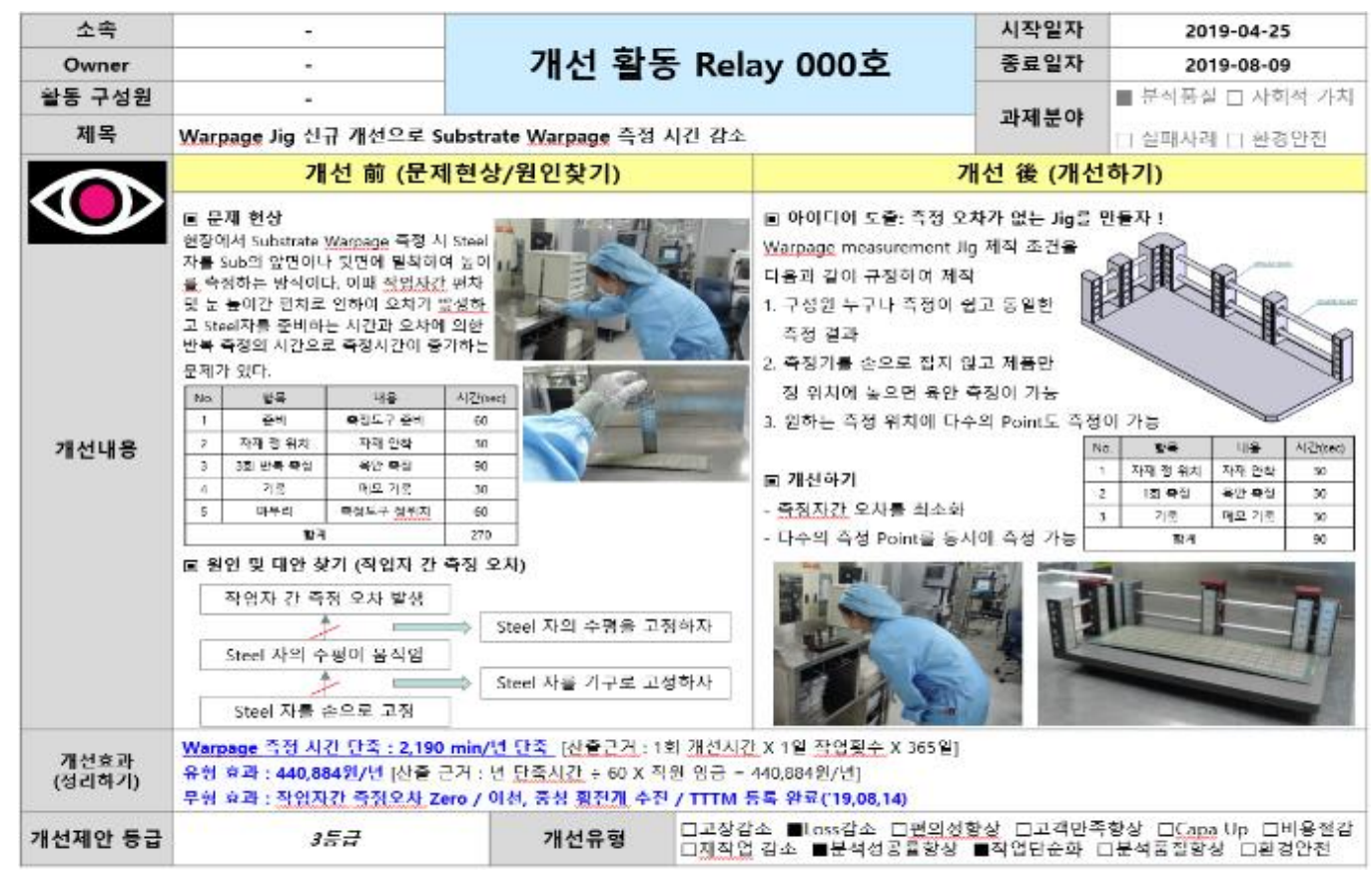

[그림 14] 현장 사례 2

[Fig. 14] Field Case 2

[그림 14] 현장 사례 2는 원인분석 과정에서도 문제의 결과를 제거할 수 있는 방법을 소개하여 쉽고 빠르게 해결안을 찾는 방법을 제시한 컨설팅 사례이다.

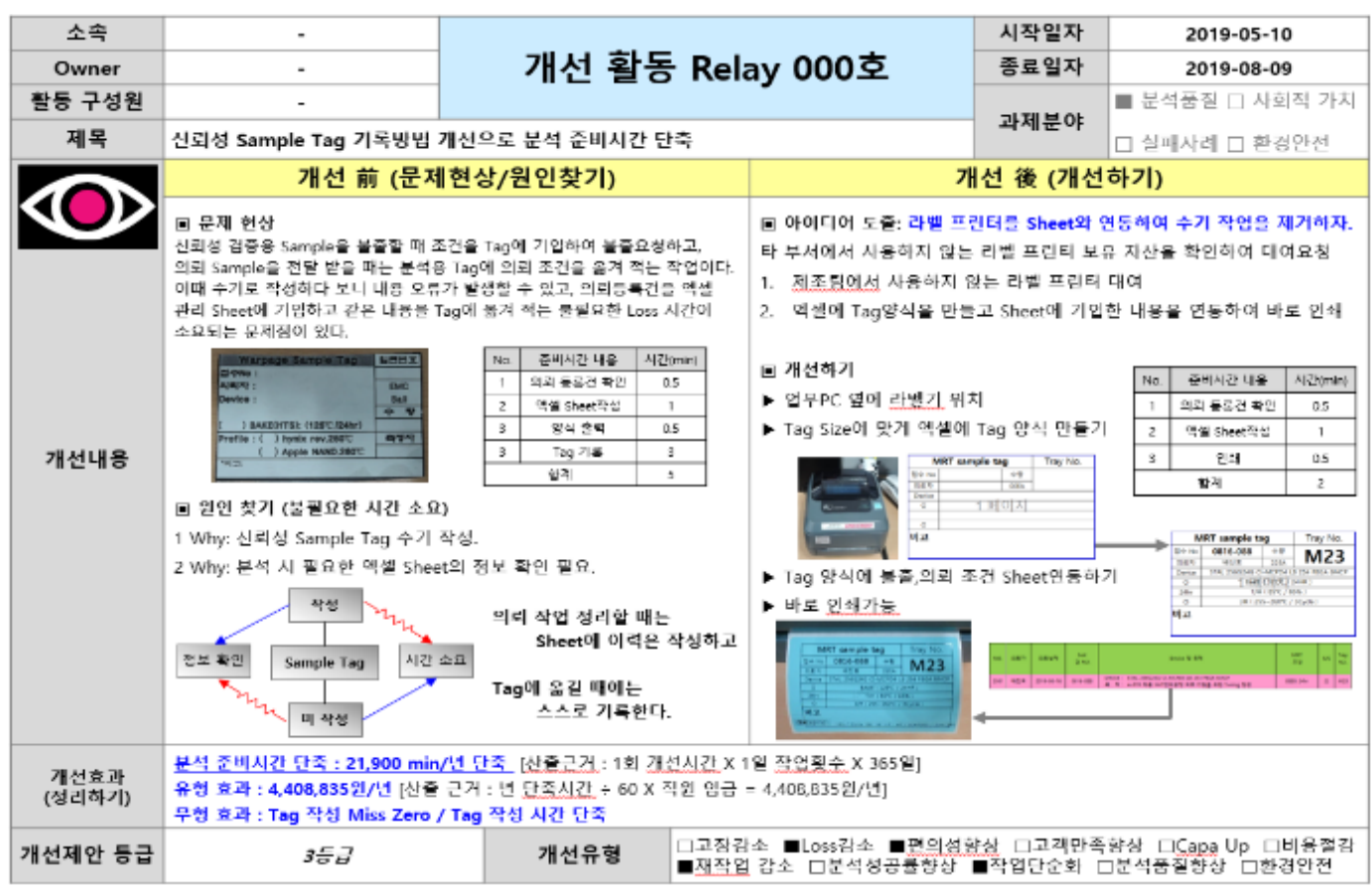

[그림 15] 현장 사례 3

[Fig. 15] Field Case 3 
[그림 15] 현장 사례 3은 원인 분석의 과정에서도 나타난 모순을 해결할 수 있도록 컨설팅 하여 바로 아이디어를 찾을 수 있는 아이디어를 제시한 사례이다.

\section{4. 적용 결과}

\section{1 문제해결 프로세스의 필요성에 대한 사전조사}

설문은 현장에서 직접 생산 및 개선 활동을 하는 현장 작업자와 정비사 147 명의 교육 대상자를 대상으로 실시하였다

[표 1] 개선 경험이 없는 이유

[Table 1] Reasons for No Experience in Improvement

\begin{tabular}{|c|c|c|c|}
\hline 구분 & 시간부족 & 관심부족 & 어려워서 \\
\hline 인원 & 3 & 8 & 13 \\
\hline 점유율(\%) & 11.76 & 35.29 & 52.94 \\
\hline
\end{tabular}

“개선 제안이 업무에 필요하다고 생각 하십니까?” 라는 질문내용에서 147 명 모두 필요하다는 답변 하였으며 “개선 제안의 경험이 있습니까?” 라는 질문에서 24명인 $19.51 \%$ 가 경험이 없다고 답변하였다. 이 24명에게 “왜 경험을 하지 못했습니까? “ 라는 질문에는 [표 1]과 같이 어려워서 경험하지 못했다는 답변이 13 명 $52.94 \%$ 로 가장 높게 나타났으며 관심 부족이 8 명으로 $35.29 \%$, 시간 부족이 3 명으로 $11.76 \%$ 를 차지하였다.

[표 2] 적용한 문제해결 과정

[Table 2] Applying Problem Solving Process

\begin{tabular}{|c|c|c|c|c|}
\hline 구분 & $\mathrm{QC}$ 스토리 & 6시그마 & 트리즈 & 회사 제공 \\
\hline 인원 & 0 & 9 & 12 & 159 \\
\hline 점유율(\%) & 0 & 5.00 & 6.67 & 88.33 \\
\hline
\end{tabular}

개선에 경험이 있는 123 명을 대상으로 추가 질문을 하였으며 “개선을 할 때 어떤 프로세스를 적용 했습니까? “ 라는 질문을 중복으로 선택이 가능하게 조사한 결과 [표 2] 와 같이 전체 선택 180 건 중에 회사에서 제공하는 프로세스를 사용하였다는 답변이 159 건으로 $88.33 \%$ 를 차지하여 압도적인 차이를 보였다.

“적용한 문제해결 프로세스를 형식적으로 사용 했습니까?” 라는 질문에 ” 그렇다” 고 답변한 사람은 87 명으로 $70.73 \%$ 를 차지하였고 “그렇지 않다 “라고 답변한 사람은 36 명으로 $29.27 \%$ 를 차지하였다. 그리고 마지막으로 ”현장에 적합한 문제해결 프로세스가 필요하다고 생각합니까?” 라는 질문에 필요하다고 답변한 사람이 119명으로 $96.75 \%$ 를 차지하였고 불필요하다고 답변한 사람은 4 명으로 $3.75 \%$ 를 차지하면서 대부분이 필요하다는 답변을 하였다. 


\section{2 개선 변리사 제도 도입 전, 후 과제 해결 건수 비교 결과}

[표 3] 과 같이 개선 변리사 제도 도입 전에는 문제 해결 건수가 2016년에 9건, 2017년에 8건으로 나타났으며 표준 등록도 2016년 1건 $11.11 \%, 2017$ 년 1건 12.05\%로 저조 하였으나 개선 변리사 제도 도입 후의 문제 해결 건수는 2018년 181건, 2019년 162건으로 크게 증가 하였으며 표준 등록도 2018년 64건으로 $35.36 \%, 2019$ 년 71건 43.83\%로 크게 증가 하였다.

[표 3] 연도별 문제해결 건수 비교

[Table 3] Comparison of the Number of Problem Solving

\begin{tabular}{|c|c|c|c|c|}
\hline 연도 & 2016 & 2017 & 2018 & 2019 \\
\hline 표준 등록(건) & 1 & 1 & 64 & 71 \\
\hline 문제해결(건) & 9 & 8 & 181 & 162 \\
\hline 표준 등록률(\%) & 11.11 & 12.05 & 35.36 & 43.83 \\
\hline
\end{tabular}

개선 변리사 제도를 도입한 후 구성원들에게 개선 변리사의 필요성에 대해서 조사하였다. 그 결과 “매우 필요하다.” 는 답변이 $26.0 \%$, “필요하다.” 는 답변이 $66.9 \%$ 로 전체의 $92.9 \%$ 를 차지했다. 즉, 개선 변리사 제도의 도입이 효과가 있다는 것이 확인 되었다. (응답 구성원: 323 명, 응답률: $74.6 \%$ ) 추가적으로 개선 지도사가 필요한 이유에 대해서 구성원들에게 조사하였다. 그 결과 시간절약 $29.4 \%$, 중복 개선 방지 $25.1 \%$, 의미 전달 $20.2 \%$, 동기부여 $17.1 \%$, 벤치마킹 $8.2 \%$ 의 순으로 나타났다. 해당 결과로 볼 때 개선 변리사 제도의 도입이 긍정적인 결과를 생성한다고 볼 수 있다. (응답 구성원: 391 명, 응답률: $90.3 \%$ ) 지속적인 개선 활동 참여 여부 조사 결과 개선 변리사 제도 도입 후 지속적으로 “개선 활동에 참여 하겠는가” 에 대해 구성원들의 질문을 구한 결과 “매우 참여하고 싶다.” 는 답변이 $5.4 \%$, “참여하고 싶다.” 는 답변이 $72.4 \%$ 로 전체의 $77.8 \%$ 가 지속적인 개선 활동에의 참여 의사를 보였다. (응답 구성원: 194 명, 응답률: $44.8 \%$ ) 개선 활동 필요성 여부 조사 결과 개선 활동의 필요성을 확인하기 위해서 개선 활동이 필요한지에 대한 조사를 실시하였다. 그 결과 “매우 필요하다.” 고 답한 구성원이 $20.2 \%$, “필요하다.” 고 답변한 구성원이 $77.0 \%$ 로 $97.2 \%$ 가 필요하다고 답변하였다. (응답 구성원: 331 명, 응답률: $76.4 \%$ ) 개선 활동이 필요하지 않은 이유에 대해서 조사했다. 그 결과 58 명이 답변하였으며, 형식적인 활동이 $51.4 \%$, 업무량의 과다가 $37.0 \%$ 를 차지하였다.

\section{5. 결론}

본 논문은 산업 현장의 다양한 문제 상황에서 유연하고 독창적이면서 융합 적인 문제해결 방법론을 연구하여 기업 내의 개선 활동을 구성원들이 자발적으로 참여 할 수 있도록 유도하고, 이를 단편적인 개선에서 지속적인 활동으로 연결시키기 위해 개선 변리사 제도를 고안하였다. 
개선변리사란 제공되는 문제해결 프로세스를 기반으로 개선 활동에 대한 컨설팅과 보고서를 돕고 사내 표준 등록에 대해 심의하고 등록하는 사람을 말한다. 개선 변리사는 현장 개선 내용에 대해 제안서 및 컨설팅 보고서 작성에 도움을 주고, 개선과 관련된 선행 표준을 조사하고 표준의 범위를 확인 후 등록한다. 그리고, 구성원의 동기부여 지원과 현장 구성원의 자율적인 개선 활동을 위한 마인드를 고취 시키는 역할을 하게 된다

문제해결 프로세스를 지도하여 성과를 이끌어 내는 개선 변리사 활동은 600 명 규모의 조직에 18 개월 간 실시하고 그 효과를 확인하였다.

\section{6. 감사의 글}

This research was supported by Basic Science Research Program through the National Research Foundation of Korea (NRF) funded by the Ministry of Education (2018R1D1A1B07049244)

\section{References}

[1] Sangbok Lee, Speaking of the development plan for quality division groups. Let's make a Korean division groups model, KSAM Quality and Creativity, (2014), Vol.39, No.10, pp.66-69.

[2] Changnam Kim, The birth of new improvement activities Concrete methodology, KSAM Quality and Creativity, (2012), Vol.37, No.5, pp.98-104.

[3] Kangin Lee, "Problem-solving process" tailored to our field is the Answer, KSAM Quality and Creativity, (2011), Vol.36, No.10, pp.48-53.

[4] Sangbok Ree, Let's make a Korean Quality Circle, KSAM Quality and Creativity, (2014), October, pp.65-69.

[5] Wanbok Park, A Case Study on the Improvement Activities of Quality Circle by Improving Attorney System, Journal of Korean Society for Quality Management, (2020), Vol.48, No.1, pp.227-239, DOI: https://doi.org/10.7469/JKSQM.2020.48.1.227

[6] Dongseok Oh, The introduction of TRIZ in the field Circles, Fall Conference of the Korean Society for Creation and Application, (2016), November 18, Seoul, Korea.

[7] Job Korea, $72 \%$ of employees are difficult to prepare business documents, Gyeongbuk Daily Newspaper, September $26,(2005)$

[8] Hyukjong Park, The Secret of Writing Documents that Inspires CEOs, Future and Management, (2010)

[9] https://www.kpaa.or.kr/kpaa/member/download.do?clickPage=31, November 23, (2019) 